\title{
O AVANÇO CIENTÍFICO SE DÁ AO ACASO? O conhecimento da atmosfera no contexto histórico
}

\section{DOES SCIENTIFIC KNOWLEDGE HAPPEN BY CHANCE? KNOWLEDGE OF THE ATMOSPHERE IN THE HISTORICAL CONTEXT}

\author{
Lucí Hidalgo Nunes ${ }^{1}$ \\ ${ }^{1}$ Universidade Estadual de Campinas (UNICAMP), Campinas, SP, Brasil
}

Correspondência para: Lucí Hidalgo Nunes (luci@ige.unicamp.br)

doi: 10.12957/geouerj.2019.40948

Recebido em: 15 ago. 2018 | Aceito em: 24 out. 2018

\section{RESUMO}

Por meio de exemplos, procurou-se demonstrar que para a compreensão da evolução dos conhecimentos nas ciências atmosférica é de suma importância considerar não apenas os mecanismos físicos, mas também o contexto histórico no qual certo conhecimento foi alcançado. Isso se justifica pelo fato de que os avanços da ciência refletem o momento histórico e, assim, os valores políticos, econômicos, sociais e culturais, bem como as necessidades da humanidade de um dado momento. Os primeiros conhecimentos do comportamento da atmosfera se deram no campo da agricultura e tiveram base empírica; todavia, a especulação dominou os conhecimentos atmosféricos por longo tempo. Em outros momentos, a observação, a experimentação e a teoria direcionaram os avanços na área. Sendo um conhecimento estratégico, a compreensão dos processos atmosféricos se associou de forma intrínseca a diversos eventos cruciais da História, como as grandes navegações na Idade Moderna e as guerras: a teoria das frentes, por exemplo, foi desenvolvida durante a Primeira Guerra Mundial, sendo seu nome uma analogia às frentes de batalha. Atualmente os estudos adquirem uma natureza mais integrada, mas são ainda dominados por interesses políticos e mesmo geopolíticos.

Palavras-chave: atmosfera. história. progressos científicos. teoria.

\section{ABSTRACT}

By means of examples, it was tried to demonstrate that for the understanding of the evolution of the knowledge in the atmospheric sciences it is of paramount importance to consider not only the physical mechanisms, but also the historical context in which certain knowledge was reached. This is justified by the fact that the advances of Science reflect the historical moment and thus the political, economic, social and cultural values, as well as the needs of humanity, at a given moment. The first knowledge of the behaviour of the atmosphere occurred in the field of agriculture and had empirical basis; however, speculation dominated atmospheric knowledge for a long time. At other times, observation, experimentation, and theory drove advances in the area. Being a strategic knowledge, the understanding of atmospheric processes was intrinsically associated with several crucial historical events, such as the great navigations in the Modern Age and wars: the theory of fronts, for example, was developed during World War I, being its name an analogy to the battle fronts. Nowadays studies acquire a more integrated nature but are still dominated by political and even geopolitical interests.

Keywords: atmosphere. history. scientific advances. theory.

\section{INTRODUÇÃO}

Ainda que os progressos científicos possam ser vistos como independentes de quaisquer agentes condicionadores, os avanços da ciência não são fortuitos; pelo contrário, eles são historicamente 
marcados refletindo, assim, as prioridades e interesses de um dado momento. Portanto, as necessidades de uma determinada época impulsionaram o desenvolvimento científico, que se deu de forma consonante com as instituições existentes, o que reforçou e respaldou os arranjos sociais em vigor.

Como a ciência está intrinsecamente associada à estrutura social vigente, a análise das maneiras como se deram os avanços científicos revela erros, equívocos e até preconceitos próprios de um determinado momento. Ela demonstra, ainda, que o desenvolvimento científico não é sequencial, sendo constituído de avanços e retrocessos.

O presente estudo discute como o desenvolvimento da ciência atmosférica esteve fortemente relacionado ao contexto histórico em que ocorreu, reforçando que um conhecimento abrangente dessa área científica deve ser ancorado não apenas no entendimento dos processos do tempo e do clima, mas também nos motivos pelos quais determinadas informações foram mais prioritárias em um dado momento. Exemplos são fornecidos para ilustrar estes pontos: o conhecimento empírico de controle e armazenamento de água para obter boas colheitas por civilizações antigas da Ásia; o conhecimento da circulação da atmosfera no período das grandes navegações, os avanços das condições do tempo verificados durante as guerras mundiais, e o melhor conhecimento dos processos da alta atmosfera durante a guerra fria.

Os exemplos apresentados retratam as informações mais conhecidas e que tiveram maior peso na construção do conhecimento geral dos processos atmosféricos.

\section{Das primeiras civilizações ao Império Romano: o conhecimento empírico e especulativo do tempo e do clima}

Povos da antiguidade, como egípcios, gregos, árabes e chineses, criaram base empírica do conhecimento das condições meteorológicas e climáticas pela observação, que se constituiu em elemento basilar na organização das suas vidas e das suas atividades (Alcoforado, 1997). 
Um exame inicial das primeiras civilizações humanas já revela a importância do conhecimento das chuvas e das cheias: não se pode falar das civilizações egípcias ou do Crescente Fértil sem relacioná-las às cheias do Rio Nilo e à importância dos Rios Tigre e Eufrates (NUNES, 1999).

O alvorecer da história da humanidade está profundamente ligado ao florescimento da agricultura e à domesticação dos animais, que possibilitaram aumento da oferta de alimentos e, como consequência, da população, promovendo o surgimento das primeiras civilizações. Esse fato se constitui em um marco na capacidade humana de contornar os limites ambientais, utilizando o trabalho, as relações sociais e a tecnologia para obter mais alimentos.

Nesse período, o conhecimento empírico, mais do que o teórico, era importante. Em sociedades como as do Crescente Fértil e do antigo Egito o conhecimento estava voltado para o desenvolvimento de maneiras de como obter boas colheitas, em particular, em formas como controlar e armazenar água para estender o período de crescimento das culturas. No Crescente Fértil, por exemplo, foram desenvolvidos padrões de irrigação e sofisticados sistemas de controle de inundações, sendo que a área era intersectada por diques (JOHNSON; LEWIS, 1995, SIMMONS, 1996). Além disso, escavações arqueológicas atestam que a orientação das cidades era condicionada pela circulação dos ventos, de modo a aliviar o estresse causado pelo calor (SULMAN, 1982).

A conexão desses povos em relação às situações atmosféricas aparece em suas crenças. Na Babilônia reino ao sul da Mesopotâmia -o deus mais importante era Marduk, que comandava toda a atmosfera. Esse povo procurava predizer as condições do tempo com base nas observações dos astros celestes, das nuvens e de fenômenos ópticos, como halos. Menção a essas ocorrências foram também encontradas entre os assírios (CROWDER, 1996).

A antiga civilização egípcia tinha base rural sendo, portanto, altamente dependente das chuvas e das cheias do Rio Nilo - a principal artéria e canal de comunicação nas terras densamente cultivadas em ambas as margens do rio. A construção de diques era elemento-chave na regulação das águas (SIMMONS, 1996). Todos esses arranjos demandavam alta organização governamental, de forma a 
mobilizar e direcionar os esforços, estando no centro de toda a estrutura social, que era bastante estratificada. A grande dependência de toda a sociedade das cheias do Nilo fez com que as secas ocorridas em alguns anos (provavelmente associadas a episódios de El Niño) tenham causado insurreições políticas, como entre 2180 e 2160 AC (FAGAN, 2000). O legado dos egípcios para o conhecimento ambiental é enorme, especialmente porque eles reportaram as cheias e secas com detalhe, constituindo-se em informação de enorme relevância para o conhecimento das condições pretéritas.

Crowder (1996) lembra que também os chineses usavam a observação dos astros para monitorar as mudanças diárias e sazonais das condições atmosféricas, inclusive com a criação de um calendário.

Em contraste a esse conhecimento empírico, alguns esforços para entender os processos da atmosfera tiveram natureza altamente especulativa. Tentativas para prever o tempo eram baseadas em eventos astronômicos e astrológicos em algumas civilizações. Caldeus, egípcios, babilônios, assírios e chineses associaram algumas doenças a planetas e estrelas, muitas vezes de forma fatalista. Pitágoras (580 a 489 AC) acreditava que proporções incorretas dos quatro elementos - fogo, terra, água e ar estariam associadas a doenças específicas. Essa explicação falaciosa é considerada por alguns cientistas como um obstáculo real para o desenvolvimento da medicina por séculos. (SULMAN, 1982).

Um contraponto às explicações supersticiosas e míticas para os problemas de saúde veio de Hipócrates, tido ainda hoje como pai da medicina. Em sua obra Ares, Águas e Lugares (400 AC) ele procurou relacionar a causa das doenças aos fatores climáticos e aos hábitos dos indivíduos, rechaçando a influência divina e punitiva como explicação para os males da saúde. Ainda no período clássico, o tratado Meteorologica (Aristóteles, 340 AC), respeitado como uma autoridade na área por cerca de 2000 anos, merece especial atenção. Nesse ensaio, Aristóteles aplicou seus princípios de filosofia, apresentando os eventos da atmosfera (meteoros) como componentes de uma doutrina que incluía todo o mundo natural (CROWDER, 1996; JANKOVIĆ, 2000). O tratado é baseado em analogias ao invés de interpretações demonstráveis, combinando observações com especulações sobre a origem dos fenômenos celestes. Ainda que com o passar do tempo a maior parte das informações tenha sido 
reconhecida como incorreta, o termo Meteorologia deriva desse tratado, considerado o mais antigo sobre os processos atmosféricos. Lamb (1972), Acot (2003) e Boia (2004), entre outros, destacam que Aristóteles descreveu o "caráter natural" dos homens em diferentes regimes climáticos, apresentando argumentos que comprovariam a pretensa superioridade dos gregos em relação aos outros povos da sua época. Theophrastus, discípulo de Aristóteles, descreveu e relacionou nuvens à direção dos ventos a partir da observação de numerosos sinais associados à chuva, ventos e condições de tempo estável (CROWDER, 1996).

Foram também os gregos que propuseram pela primeira vez a existência de leis que governariam a variabilidade dos processos naturais - provavelmente uma projeção no universo da vida ordenada da polis grega, onde um cidadão gozava de considerável liberdade, embora sua vida estivesse vinculada a leis impessoais (PHILANDER, 1998).

O interesse pelos padrões espaciais e temporais do tempo atmosférico já estava presente por volta de $300 \mathrm{AC}$, conforme testemunham os textos de Aratus de Solis (Phaenomena) e de Virgílio (Georgics, $37 \mathrm{AC})$. O primeiro foi um poeta que em sua obra descreveu as constelações e outros fenômenos celestes, em particular, na segunda parte dessa obra, denominada Diosemeia (CROWDER, 1996; JANKOVIĆ, 2000). Por sua vez, Virgílio apresentou informações sobre o tempo atmosférico e princípios agrometeorológicos na forma de poesia ao invés de um tratado didático (JANKOVIĆ, 2000).

Em 25 DC Pomponius Mela, reconhecido como o primeiro geógrafo do Império Romano, formalizou um sistema de zonas climáticas composto por cinco setores: uma zona frígida e uma temperada ao norte e ao sul, e uma zona tórrida, ao centro. Em seus escritos, Mela afirmava que as duas zonas temperadas eram passíveis de ser habitadas, mas apenas a do norte era conhecida. Contudo, ele argumentou que a passagem do norte para o sul seria impossível, dada a necessidade de atravessar a zona tórrida, no qual o calor seria insuportável. O oceano em torno da Terra seria dividido em quatro mares, sendo o Mediterrâneo o mais importante. Ainda que destituída de mais detalhes e informações, 
a classificação climática proposta por Mela foi transmitida ao longo de muitos séculos (MC KNIGHT, 1996; ENCYCLOPAEDIA BRITANNICA, ON LINE).

Várias civilizações relacionaram as condições do tempo a divindades: os egípcios, por exemplo, associavam os ventos ao deus Seth e tinham grande devoção ao deus do sol Ra, e à Osiris, que comandava os movimentos dos astros (CROWDER, 1996). Para os gregos, Zeus - a mais poderosa divindade - era responsável pelas intempéries. Na mitologia nórdica, Thor representava as forças da natureza, em particular, as tempestades e os trovões (em inglês, thunderstorms e thunders, respectivamente, derivações do nome Thor) (CROWDER, 1996; CANDIDO; NUNES, 2012). Além disso, conforme apontado por Nunes (1999), em inúmeras sociedades as decisões políticas eram tomadas com base em oráculos e deuses associados às forças da natureza. Burroughs et al (1996) assinalam que condições de tempo e clima estão presentes no folclore e nos provérbios das mais diversas civilizações, e que em diversas delas havia ritos e sacrifícios para que os deuses produzissem condições favoráveis.

\section{O conhecimento da atmosfera na Idade Média}

Contrastando com a opinião prevalecente de obscurantismo na Idade Média, a ciência desse período deixou vasto legado, fruto de um complexo arranjo entre religião e cultura medievais. No campo aplicado, surgiram inovações técnicas como o desenvolvimento do moinho de vento, da bússola magnética e melhorias no projeto de navios, que promoveram ganhos para a navegação.

Apesar desses exemplos, a ciência da Idade Média era quase que exclusivamente teórica, com pouca ou nenhuma observação da natureza. Filósofos naturais se baseavam em deduções lógicas de situações auto evidentes para elucidar fenômenos naturais, relutando em fazer medições para checar suas inferências, pois acreditavam que as impressões imperfeitas dos sentidos não eram confiáveis (PHILANDER, 1998). Superstições e temores, que davam suporte à astrologia e à alquimia, também faziam sombra à ciência naquele tempo. No final da Idade Média essa situação começou a mudar e a Ciência passou a se estabelecer a partir de métodos experimentais: o mais antigo registro diário dos fenômenos meteorológicos locais foi mantido por William Merle, reitor de Driby entre 1331 e 1347 
(PRIBYL, 2017), que compilou informações do tempo e do clima especialmente em Lincolnshire e Oxford (Inglaterra).

A contribuição árabe para vários campos da ciência, como matemática, é bem conhecida. No que diz respeito à atmosfera, os árabes conheciam o ritmo dos ventos, como pode ser atestado pela descrição do geógrafo Abu Zayd sobre as características físicas e a importância das monções (basadra), descrita em in 916 (FAGAN, 2000). Avanços no conhecimento de fenômenos óticos da atmosfera são também atribuídos aos árabes. No entanto, a ciência árabe - uma mistura da filosofia natural, religião islâmica, astrologia e folclore - não era capaz de explicar os mecanismos por trás das variações espaciais e temporais dos fenômenos atmosféricos.

\section{Idade Moderna: progressos no conhecimento da circulação atmosférica}

Nos primórdios do século XV surgiu o Renascimento, período marcado por diversas descobertas que colaboraram para o avanço do conhecimento da atmosfera. Uma das primeiras contribuições foi a teoria de Nicolau Copérnico, que estabeleceu que a terra realiza um giro completo em torno de seu próprio eixo no período de um dia, e ao redor do sol em um ano, base para a explicação dos períodos de solstício e de equinócio (CROWDER, 1996).

Esse foi também o período das grandes navegações: exploradores atravessaram o Oceano Atlântico e iniciaram a colonização do Novo Mundo, inaugurando uma fase de grande impulso para o conhecimento dos ventos.

A experimentação foi uma das marcas desse período. A invenção de instrumentos como o anemômetro inventado por Leon Battista Alberti e mais tarde aperfeiçoado por Leonardo da Vinci (1450), o termômetro de Galileu Galilei (1593) e o barômetro de mercúrio de Evangelista Torricelli (1643), possibilitaram a medição sistemática das condições do tempo (OLIVER; HIDORE, 2002), refletindo a tendência desse período em estudar e demonstrar os fenômenos da natureza. 
Várias descobertas quanto à circulação da atmosfera foram feitas nesse período, entre elas, o reconhecimento de uma zona de ar seco e ventos fracos denominada em inglês de Horse Latitudes. Quando as caravelas passavam por esse local, no meio do oceano, a ausência de ventos, associada à escassez de chuvas, prolongava sobremaneira as viagens. Como as caravelas transportavam cavalos, que não existiam no continente americano antes dos europeus, muitas vezes era preciso sacrificar a carga (MCKNIGHT, 1996; THE COLUMBIA ELECTRONIC ENCYCLOPEDIA, 2003). Hoje se sabe que essa zona de calmaria corresponde ao ramo subsidente da célula de alta pressão subtropical, caracterizada por ventos fracos e secura pela compressão adiabática do ar. Bueno (1998) lembra que os navegadores portugueses que chegaram pela primeira vez à costa brasileira, em 22 de abril de 1500, relataram que os navios foram mantidos nessa área de vento muito fraco (calmaria) por cerca de 10 dias, começando no final de março.

Os marinheiros notaram, também, que na zona próxima ao Equador os ventos ascendem, denominando esse setor de doldrum, hoje mais conhecido como Zona de Convergência Intertropical (ZCIT).

Os primeiros estudos sobre padrões climáticos globais apareceram um pouco mais tarde. Em 1666, a Sociedade Real de Londres preparou um tratado com instruções para coletar dados sobre ventos e correntes. Em 1686 o astrônomo britânico Edmund Halley apresentou um estudo sistemático geral dos ventos alísios e das monções, identificando o aquecimento solar como a causa dos movimentos atmosféricos e estabelecendo a relação entre a pressão barométrica e a altura acima do nível do mar.

Os ventos alísios - que convergem na região da ZCIT produzindo tempestades convectivas - são conhecidos por facilitar a rota dos navios pelo Atlântico no período das grandes navegações. É interessante notar que nas línguas germânicas, como inglês e alemão, o nome alísios (trade winds, Geshäftswinde) significa, literalmente, ventos do comércio, o que confirma suas importâncias para o estabelecimento de rotas comerciais naquele período.

A monção - supostamente conhecida desde 115 AC, quando o grego Eudoxus de Cyzicus fez duas viagens do Mar Vermelho para a Índia (FAGAN, 2000) - é uma circulação sazonal complexa, 
presente em diversas áreas do mundo, regulada por vários fatores, entre eles, o aquecimento diferencial entre terra e mar. Em áreas onde prevalece esse regime de ventos, durante o verão, quando o continente é mais aquecido, ventos úmidos sopram do mar (maior pressão) para a terra (menor pressão), invertendo a direção alguns meses depois. Usando observações coletadas por marinheiros, no final do século XVII, Edmond Halley - mais conhecido por seus feitos na astronomia - organizou um fluxograma meteorológico dos oceanos tropicais, explicando a circulação das monções como uma alteração regional dos ventos alísios. (FAGAN, 2000).

Avanços na explicação da circulação global receberam forte aporte em 1735, quando o britânico George Hadley descreveu o desvio do movimento atmosférico - aspecto importante para o conhecimento dos ventos alísios. Sua avaliação foi enriquecida um século depois pelo estudo do engenheiro e matemático francês Gaspard-Gustave Coriolis, que explicou essa inflexão quantitativamente, mostrando que a rotação da Terra afeta os ventos, desviando-os para a esquerda no Hemisfério Sul e para a direita, no Hemisfério Norte.

Ainda no século XVIII Heinrich Brandes elaborou os primeiros mapas sinóticos, a partir de informações das primeiras redes de coleta de dados, instituídas pela Sociedade Real Britânica, pela Academia de Ciências Francesa e pela Sociedade Meteorológica Mannheim (CROWDER, 1996). Esse esforço pode ser visto como um prenúncio para o entendimento de que processos de diferentes áreas se conectam. No início do século XIX uma contribuição consistente para a compreensão do movimento atmosférico foi apresentada pelo geógrafo alemão Alexander von Humboldt, cujos estudos foram baseados em uma visão global e em relações entre a natureza viva e as demais condições de existência na Terra - uma perspectiva inovadora. Em 1817 ele começou a coletar dados em vários locais, encontrando diferenças significativas ao longo da mesma latitude, explicadas em termos da distribuição terra-mar, modificadas localmente por características geográficas (FAGAN, 2000).

Os interesses econômicos do Império Britânico na Índia reforçaram os estudos para a compreensão dos padrões de vento no século XIX, em especial, das monções. Episódios de seca em anos de monções fracas se relacionavam ao deslocamento da população para fugir da fome, aos surtos de doenças, como 
cólera, e à grande mortandade de rebanhos. Após um episódio de seca desastrosa em 1866, foi criado o Serviço Meteorológico Indiano, que forneceu informações meteorológicas diárias até 1888 (FAGAN, 2000).

Várias das abordagens para entender o processo das monções procuravam observar a existência de ciclicidades nos eventos, aspecto notavelmente presente em grande parte da ciência produzida no período: nessa mesma época, por exemplo, foi proposto pelo geógrafo americano Morris Davis os ciclos geomorfológicos para o entendimento da evolução das paisagens. No caso da busca do entendimento dos mecanismos das monções, tentou-se correlacionar a variabilidade da precipitação com o ciclo de manchas solares. Ainda que haja registros de manchas solares no Oriente que datam de 28 AC (OLIVER; HIDORE, 2002), os esforços para demonstrar que o comportamento cíclico da atividade solar se reflete nas variações do clima ganharam expressão a partir da contribuição do astrônomo alemão Samuel Heinrich Schwabe, que em 1843 descobriu que as manchas solares variam de maneira regular e previsível (BURROUGHS, 1997).

Outra contribuição para o entendimento das monções procurou correlacioná-las com o padrão global da circulação atmosférica, teoria que algum tempo depois foi comprovada. Sir Gilbert Walker, Diretor do Serviço Meteorológico Indiano no início do século XX, perseguiu como seu objetivo principal a previsão da flutuação das monções, relacionadas às fortes secas na Índia. Walker usou dados de diferentes lugares para estabelecer a relação entre a monção e a circulação atmosférica global, e publicou alguns artigos sobre oscilação da pressão atmosférica em diferentes escalas entre diversas partes do mundo, nomeando a mais importante de Oscilação do Sul. Contudo, apesar de sua teoria ser ancorada em suposições corretas, suas fórmulas não conseguiram correlacionar corretamente as variáveis - uma ironia, sendo ele estatístico - e dessa maneira, não conseguiam prever as monções. Algumas décadas mais tarde sua teoria foi resgatada e suas fórmulas, melhoradas. Em sua homenagem, a circulação zonal que se associa ao fenômeno ENOS (El Niño Oscilação Sul, que além do padrão usual tem as fases El Niño e La Niña) é conhecida como Circulação de Walker. Hoje se sabe que anos de fraca monção correspondem à ocorrência do El Niño. 
Enquanto isso, o geógrafo Luis Carranza, presidente da Sociedade Geográfica de Lima, publicou um artigo em 1891, chamando a atenção para uma contracorrente ocasional que flui ao longo da costa peruana. Camilo Carrillo publicou outro trabalho em 1892, relatando que os marujos Paita - que frequentemente navegam ao longo da costa - faziam alusão aos años de abundancia (anos de abundância), quando havia precipitação torrencial na costa. Em 1895, o também geógrafo Victor Eguiguren correlacionou as fortes chuvas e inundações no norte do Peru às águas mais aquecidas do Pacífico. Esses estudos tiveram base empírica e científica, com observação e procura de explicações do fenômeno que é hoje conhecido como o El Niño, assim denominado em homenagem ao menino Jesus, uma vez que ele é observado próximo ao Natal. Ainda que por muito tempo o El Niño tenha sido visto como um fenômeno local, em 1969 a influência da Oscilação Sul em muitas partes do mundo foi entendida, graças ao resgate das ideias de Walker por Jakob Bjerknes (PHILANDER, 1990).

Durante os séculos XVIII e XIX naturalistas europeus e norte-americanos passaram algum tempo em áreas tropicais, transferindo para seus museus e centros de estudo espécimes novos para os países temperados, classificados e organizados em uma ordem que obliterou conexões com seus ambientes de origem. As áreas tropicais eram (e ainda são, em alguma extensão) chamadas e tratadas como "exóticas" - um termo que carrega conotação negativa, embora a raiz linguística da palavra mostre que em sua origem o termo é definido como algo excitantemente diferente, incomum. Ao tomar este último significado (incomum) e considerando que a biodiversidade mais importante está localizada dentro dos trópicos, fica claro que o que pode ser visto como exótico é o ambiente extratropical e não o tropical, aspecto que evidencia o preconceito imperante no momento histórico e que contaminou a ciência.

Paralelamente o conhecimento da composição da atmosfera recebeu aporte da química, com estudos sobre os gases componentes da atmosfera: o primeiro avaliado em detalhes foi o gás carbônico, em 1752, seguido por outros como o nitrogênio e o oxigênio (OLIVER; HIDORE, 2002). O matemático francês Jean Baptiste Fourier foi o primeiro a reconhecer os efeitos dos gases de efeito estufa (GEE) em 1827, conhecimento complementado em 1860 pelo britânico John Tyndall, que mediu a absorção da radiação infravermelha devido à presença do $\mathrm{CO} 2$ e do vapor d'água, e sugeriu que períodos mais frios poderiam estar associados à diminuição do efeito estufa pelo gás carbônico. Em 1896, o sueco 
Svante Arrehenius calculou o efeito do aumento da concentração de GEE; estimando que a temperatura aumentaria entre 5 e 6 graus Célsius caso a concentração de gás carbônico dobrasse (BARBIN, 2006).

Entre o século XIX a década de 1970 do século passado o mundo testemunhou, também, o neocolonialismo, que correspondeu à ocupação da África pelas potências industrializadas europeias, interessadas na exploração dos vastos recursos desse continente. A ocupação e a exploração tinham por justificativas alegações pseudocientíficas, em grande parte embasadas em condições atmosféricas, conhecidas como determinismo geográfico: por exemplo, altas temperaturas e umidade tornariam os habitantes dos trópicos preguiçosos, enquanto mudanças frequentes na pressão barométrica tornariam os moradores de regiões temperadas intelectualmente mais ágeis (BOIA, 2004). Essas argumentações foram apresentadas como razões "aceitáveis" para submeter outras nações e povos aos interesses dos europeus. Somente na terceira década do século XX o determinismo ambiental - baseado em falsas afirmações científicas das ciências atmosféricas - foi rejeitado, por ser desprovido de base científica real.

\section{As descobertas do século XX}

O século XX experimentou o mais extraordinário progresso científico e tecnológico da história da humanidade até então. Nesse período, o interesse no conhecimento das condições atmosféricas de todo o globo foi condicionado por necessidades de natureza militar, política e econômica, de modo que muitos dos avanços seguiram um caminho pré-determinado.

O estudo da composição, estrutura e característica dos gases componentes da atmosfera teve continuidade, com contribuição de vários cientistas. Em 1940 o britânico Guy Stewart Callendar afirmou que o aquecimento global se deve ao aumento do gás carbônico pela queima de combustíveis fósseis. Em 1957 o físico americano Roger Revelle e o austríaco radicado nos Estados Unidos especializado em físico química, Hans Eduard Suess, associaram as mudanças climáticas ao aumento dos GEE na atmosfera (BARBIN, 2006). No mesmo ano, o americano Charles Keeling iniciou 
medições de gás carbônico no remoto observatório de Mauna Loa, Havai, que continuam até o presente. A série mostra que mesmo em locais livres de interferências próximas, é possível observar o aumento constante da concentração de gás carbônico (OLIVER; HIDORE, 2002).

Nas primeiras décadas do século passado a ciência era ainda marcada pela busca de ciclos para antecipar as maneiras pelas quais os processos naturais funcionariam, marcando uma concepção mecanicista da Terra. Um exemplo dessa perspectiva é a teoria proposta pelo matemático sérvio Milutin Milankovitch nos anos 1920, com o objetivo de explicar como alterações nos parâmetros orbitais teriam causado avanços e recuos das calotas polares. Ele sugeriu que os ciclos climáticos de longo prazo estariam atrelados a mudanças de ordem astronômica, com três grandes ciclos: excentricidade - que diz respeito à alteração na geometria da elipse do movimento da terra, com variação na ordem de 100.000 anos; obliquidade - que dura cerca de 41.000 anos e é relativa ao ângulo de rotação do eixo da terra (atualmente 23027', mas que variou entre 21040' e 24030'); e precessão - a variação menos lenta (23.000 anos), que se associa à alteração na aproximação maior da terra em relação ao sol ao longo dos meses do ano (afélio/periélio). Essas mudanças influenciariam a quantidade de radiação solar que atinge diferentes partes da Terra em diferentes épocas do ano (AGUADO; BURT, 1999) e a combinação desses três ciclos definiriam as condições climáticas gerais no planeta em um dado momento. Mesmo que quase centenária, essa teoria é ainda aceita para explicar as mudanças climáticas pretéritas.

O desenvolvimento de sistemas de classificação é outra característica presente na ciência a partir do final do século XIX, com continuidade no século passado. O esquema de classificação climática mais amplamente utilizado foi desenvolvido pelo pesquisador alemão nascido na Rússia Wladimir Köppen, que utilizou uma base numérica de classificação baseada em valores anuais e mensais de temperatura e precipitação, bem como padrões de vegetação. Köppen definiu cinco zonas principais - quatro delas a partir das características da temperatura e a outra, com base na precipitação - subdivididas em subtipos, e estabeleceu uma nomenclatura que combina letras maiúsculas e minúsculas, cada uma com um significado definido (MC KNIGHT, 1996). Em 1954 o geógrafo americano Glen Trewartha incluiu mais uma zona no esquema, que corresponde aos climas das terras altas, refinada por Trewartha e 
Horn em 1980 (YNOUE et al, 2017). A primeira versão do esquema de Köppen apareceu em 1918, mas ele a redefiniu continuamente, incorporando novas medições e informações. Apesar de seu cuidado, o próprio Köppen estava insatisfeito com sua última versão e nunca considerou sua taxonomia climática como um produto acabado, ainda que até hoje ela seja amplamente usada.

Na primeira metade do século XX as duas grandes guerras mundiais deram grande impulso no conhecimento dos processos atmosféricos, uma vez que as condições de tempo e clima são informações estratégicas. Assim, a meteorologia deu inúmeras contribuições para as operações militares. Na época da Primeira Guerra Mundial, o cientista norueguês Vilhem Bjerknes estabeleceu o Instituto Geofísico de Bergen. Ele reuniu um grupo de colaboradores e desenvolveu a teoria da formação, crescimento e dissipação de ciclones de latitudes médias, que são tempestades que se formam ao longo de uma frente em latitudes mais altas. Ele observou o antagonismo entre os sistemas ao longo de um limite que separa o ar frio do ar quente, dando origem à teoria da frente polar, - cujo nome é uma clara analogia à oposição entre os exércitos durante a guerra (frente de batalha) (AGUADO; BURT, 1999).

Entre os cientistas da Escola Norueguesa, como ficou conhecido o grupo de cientistas liderados por Bjerknes, merecem destaque dois suecos. Tor Bergeron explicou o processo pelo qual gotículas e cristais nas nuvens crescem até atingir tamanho e peso que possibilitem a precipitação; batizado em sua homenagem, esse mecanismo é o mais importante para a formação de precipitação fora dos trópicos. Bergeron também propôs um esquema de classificação baseado na frequência de sistemas de ar em uma região. Carl-Gustaf Rossby, outro grande expoente da Escola Norueguesa, deixou importante legado para as ciências atmosféricas e oceanográficas, tendo sido o primeiro meteorologista a explicar os movimentos de grande escala da atmosfera em termos de mecânica dos fluidos. Sua grande contribuição, todavia, foi o reconhecimento das ondas de oeste, denominadas Ondas de Rossby. O cientista se dedicou ao estudo dos processos de grande escala e estabeleceu o valor da vorticidade como um parâmetro da circulação meteorológica (OLIVER; HIDORE, 2002; AGUADO; BURT, 1999).

Lewis Fry Richardson, um matemático inglês, desenvolveu o primeiro modelo numérico do tempo atmosférico que, entretanto, não produziu resultados muito bons, embora o método básico estivesse 
correto. Progressos nas ciências computacionais nos anos 1950 tornaram viáveis experimentos numéricos, possibilitando o desenvolvimento dos primeiros modelos da atmosfera (CROWDER, 1996; HOUGHTON, 2003).

O período da Segunda Guerra Mundial também experimentou avanços expressivos no conhecimento dos processos da alta atmosfera. Os primeiros indicativos das mudanças da atmosfera com a altitude ocorreram ainda no século XIX, com instrumentos acoplados à balões e até em pipas. Já no início da década de 1920 foi introduzida a radiossonda para coleta de informações, sendo um artefato conectado a um balão munido de um rádio que envia para a superfície medições contínuas feitas com aparelhos para coleta da pressão atmosférica, temperatura e umidade (OLIVER; HIDORE, 2002). Porém, foi durante a Segunda Guerra Mundial que uma rede eficaz de radiossondas expandiu rapidamente, provendo boa base de informações para a previsão do tempo (CROWDER, 1996). Nesse período, pilotos que atravessavam regularmente de oeste para leste, e vice-versa, notaram que era mais rápido voar para o oriente, devido à presença de ventos altos e rápidos que sopram em faixas estreitas: tratase da Corrente do Jato, que são como "rios de ar" que fluem em alta velocidade, influenciando o tempo nas médias latitudes. Os japoneses tentaram usar esse conhecimento como arma de guerra, colocando balões em alta altitude equipados com bombas que deveriam cair na costa oeste dos Estados Unidos depois de alguns dias ${ }^{1}$. A precisão das bombas era baixa, mas elas produziram efeito psicológico.

Durante a Segunda Guerra Mundial os operadores de radar descobriram que algumas intempéries causavam ecos, mascarando potenciais alvos inimigos. Para as operações de guerra foram desenvolvidas técnicas para filtrá-las, mas os cientistas começaram a estudar o fenômeno. Após a guerra, os radares passaram a ser usados para detectar precipitação, sendo desde então aprimorados para esse fim.

No período pós-guerra, a rivalidade entre as nações foi igualmente fonte de avanços nas ciências atmosféricas: durante a Guerra Fria, a competição entre os Estados Unidos e a ex-União Soviética, aliada a um período de expansão econômica, acelerou algumas descobertas, como aquelas relacionadas

\footnotetext{
${ }^{1}$ Informações podem ser vistas em: https://www.youtube.com/watch?v=jBDCsuZ5Uj8
} 
às operações aéreas, que requerem um bom conhecimento sobre as maneiras como operam os fluxos de ar nos níveis superior e inferior.

Em outubro de 1957 os soviéticos colocaram em órbita o Sputnik I e em janeiro de 1958, os Estados Unidos lançaram o Explorer I, iniciando a era em que as informações meteorológicas se tornaram disponíveis globalmente. O advento dos satélites meteorológicos ocorreu em 1960, com o TIROS I (CROWDER, 1996). Imagens de satélite associadas a registros em superfície foram usadas em 1969 por Jakob Bjerknes (filho de Vilhem Bjerknes, da Escola Norueguesa), que demonstrou a relação entre a Oscilação do Sul e os padrões anômalos verificados no Pacífico, cujas consequências podem afetar cerca de $60 \%$ do mundo.

Ainda nos anos 1960, o sistema atmosférico foi definido como caótico, por apresentar propriedades não lineares, ou seja: quando um parâmetro do sistema muda, os outros se alteram de uma maneira que não é diretamente proporcional a essa mudança. Usando um conjunto de equações para representar processos convecticvos, o autor da Teoria do Caos, Edward Lorenz, demonstu que a atmosfera é inerentemente imprevisível (BURROUGHS, 1996). Como a qualidade das previsões se associam fortemente às condições iniciais dos modelos matemáticos, dado que a atmosfera é muito sensível ao estado inicial, uma pequena mudança produz resultados muito diferentes à medida que o tempo passa, limitando a precisão das previsões de longo prazo.

Além disso, muitas taxonomias climáticas surgiram na segunda metade do século XX, em geral elaboradas para fins específicos. Algumas abordagens tiveram base empírica, ou observacional, considerando a evolução dos elementos do clima como temperatura e precipitação, enquanto outras tiveram base genética, tendo por base a dinâmica da atmosfera (AYOADE, 1986; OLIVER: HIDORE, 2002). Como exemplo de uma classificação empírica, pode se apontar aquela proposta por Thornthwaite, bastante usada para fins da agricultura. Sua formulação é calcada em dados coletados principalmente nos Estados Unidos ao invés de princípios físicos, fato que limitaria sua aplicação em outros ambientes, especialmente por subestimar a evapotranspiração potencial, ao não considerar a energia advectiva recebida de áreas distantes (CAMARGO; CAMARGO, 2000). No campo das 
taxonomias dinâmicas, uma das mais conhecidas foi proposta por Strahler, cuja base é o controle por meio das diferentes massas de ar (YNOUE, 2017). É importante destacar que abordagens baseadas na distribuição de energia e nos sistemas atmosféricos podem ser vistas como mais realistas, pois consideram a dinâmica da atmosfera, em contraposição aos esquemas globais com base em uma única regra estática na ordenação e classificação do mundo inteiro.

\section{O protagonismo contemporâneo das ciências atmosféricas}

O crescente impacto da humanidade no planeta tem engendrado efeitos dramáticos na atmosfera, como poluição do ar, chuvas ácidas, ilhas de calor e aumento de inundações e de movimentos de massa. Com isso, surge nas últimas décadas do século $\mathrm{XX}$ um novo paradigma: o ambiente é conectado em diferentes escalas. Alinhados a essa perspectiva, estudos com vistas à avaliação dos impactos humanos na atmosfera têm comandado os esforços científicos, marcando o início da era em que a ciência passa a ter uma perspectiva holística, ambiental e global.

Para essa compreensão mais integrada do sistema, houve a instalação de uma rede global de observações meteorológicas em superfície e em níveis superiores, com medições em intervalos de tempo relativamente curtos, monitorando a origem e o desenvolvimento dos fenômenos meteorológicos. Alguns instrumentos foram aperfeiçoados, como o radar, que é um instrumento eletrônico que detecta objetos a distância através da maneira como eles propagam ou refletem ondas de rádio. Como nuvens e precipitação são fenômenos detectáveis por sinais eletromagnéticos por eles refletidos, o radar é um importante instrumento para a previsão do tempo de curto prazo. 0 desenvolvimento dos satélites e o uso de sensoriamento remoto nas ciências atmosféricas igualmente contribuem para o reconhecimento do planeta como um sistema integrado, altamente dinâmico e assim mutável por diversos processos e condicionantes.

A coordenação da rede de monitoramento mundial e de alguns programas de pesquisa estão a cargo da OMM (Organização Meteorológica Mundial, em inglês, WMO). Criada em 1950 e com sede em 
Genebra, Suíça, a OMM é voltada à promoção da cooperação conjunta para a investigação de problemas como secas, inundações, poluição do ar e mudanças climáticas (https://public.wmo.int/en).

Essa perspectiva holística ganhou maior repercussão com as colocações de Paul Josef Crutzen , um dos laureados com o prêmio Nobel em 1995 por suas pesquisas que levaram ao reconhecimento do buraco na camada de ozônio na estratosfera. O químico holandês acredita que o grau de interferência humana no sistema ambiental seria um marco para o início de uma nova era na história do planeta, que ele denominou de Antropoceno (CRUTZEN 2002; 2006). Essa visão é compartilhada por autores como Whitehaead (2014) e Schwäger (2014), que reforçam que a intervenção humana no clima estaria operando em escala global. Hegerl et al (2001), Oliver e Hidore (2002) e Houghton (2003) são exemplos de autores que alertam que os efeitos dessas intervenções já seriam visíveis em diferentes sistemas do planeta.

Outros cientistas como Mackenzie (1998) e Mannion (2014) colocam as mudanças climáticas dentro de um contexto de alterações ambientais globais, no qual a Terra é tida como um sistema integrado que conecta atmosfera, corpos hídricos, fauna, flora e as influências humanas no ambiente físico.

Para alguns estudiosos do tema, um importante reforço para esse e entendimento pode ser dado pela evolução de modelos, cujos progressos se cristalizam em resoluções mais detalhadas e, portanto, com potencial para fornecer avaliações sobre alterações que se operam em todos os ecossistemas do planeta (HOUGHTON, 2003), apontando para cenários que poderiam eventualmente ser revertidos em algum grau.

Para além do mundo acadêmico, é inegável que a partir do final da década de 1980 a discussão das mudanças climáticas começou a fazer parte do cotidiano das pessoas, compondo o conteúdo programático de diversas disciplinas escolares e passando a ser assunto recorrente na mídia (NUNES, 2005). Se até recentemente os estudos sobre a atmosfera eram dominados por abordagens derivadas das ciências naturais, no qual a atmosfera era vista e estudada com base nas leis da física, os anos recentes testemunham o reconhecimento do ser humano como um dos componentes da atmosfera, já 
que as atividades humanas modificam o recebimento e a capacidade de reflexão de calor dos ambientes diversos e a própria composição da atmosfera, inclusive em termos de teor de umidade.

Ademais, observa-se nos últimos anos que o assunto mudanças climáticas não apenas compõe, mas muitas vezes encabeça a agenda de discussão política em importantes encontros de chefes das nações. Não obstante, as questões climáticas se colocam não apenas como uma questão científica, com implicações sociais, econômicas e culturais, mas também como uma questão geopolítica, presente em mecanismos de cooperação internacional (GEMENNE, 2009; ANGELO, 2016). Esse protagonismo das questões climáticas ganhou expressão por ocasião da Conferência das Nações Unidas sobre o Meio Ambiente e o Desenvolvimento, mais conhecida como a Rio-92, realizada em junho de 1992 na cidade do Rio de Janeiro. Desde então, surgiram documentos que procuram firmar compromissos conjuntos para deter as mudanças climáticas, principalmente no tocante à diminuição na emissão de gases de efeito estufa. Nessa época foi delegado ao IPCC (sigla em inglês que na língua portuguesa tem por tradução oficial Painel Intergovernamental sobre as Mudanças do Clima), órgão criado em 1988, o duplo papel de gerar e disseminar informações acerca das mudanças climáticas. A partir de 1995 passou a ocorrer anualmente as COPs (Conferência das Partes), como parte da Convenção-Quadro das Nações Unidas sobre as Mudanças Climáticas (YNOUE, 2017).

Entretanto, nesses encontros de caráter político nem sempre as discussões são comandadas por causas essencialmente ambientais, como formas para combater os efeitos de eventos extremos do clima ou, ainda, para implementar fontes de energia que sejam alternativas reais aos combustíveis fósseis. Muitas vezes as questões climáticas são usadas como moeda de troca, como aconteceu em 2005, quando a Rússia se comprometeu aderir ao Protocolo de Quioto, que visava a diminuição na emissão de gases de efeito estufa na atmosfera, em troca de entrar para a Organização Mundial do Comércio. Ainda nessa linha, Helm e Schellnhuber (2001) alertam que as incertezas que ainda existem no conhecimento científico do clima são usadas pelos mandatários de algumas nações para esconder suas verdadeiras razões para não apoiar regulações internacionais, escamoteando seus reais interesses, como a manutenção da atual base energética mundial, claramente dominada por essas nações. 


\section{CONSIDERAÇÕES FINAIS}

As necessidades humanas sempre foram o elemento propulsor do desenvolvimento científico e tecnológico. Assim, ao longo da história da humanidade, as necessidades do momento direcionaram os conhecimentos.

A extrema dependência do ser humano das condições de tempo e clima fez com que o conhecimento da atmosfera tenha sido primordial, sendo que dependendo do momento histórico esses conhecimentos ocorreram de forma empírica, como na Idade Antiguidade; de maneira quase que exclusivamente teórica, como na Idade Média; com ênfase na experimentação, como na Idade Moderna; ou encarando os processos físicos de forma mecanicista, como entre o final século XIX até as primeiras décadas do século passado. Atualmente prevalecem os esforços para uma ciência mais holística, a partir das evidências de que os subsistemas do planeta são conectados entre si.

No entanto, uma parte substancial dos problemas socioambientais do planeta, como inundações ou movimentos de massa, é deflagrada por condições atmosféricas associadas às formas de ocupação do território estando, ao menos parcialmente, associadas a causas antropogênicas. Portanto, o papel que diferentes processos desempenham na determinação do comportamento atmosférico atual e futuro deve incorporar a contribuição das ciências humanas para alcançar um conhecimento abrangente dos impactos climáticos.

Eventos calamitosos têm sido cada vez mais severos e registrados na época em que os progressos tecnológicos e científicos são os maiores da história da humanidade. Este paradoxo enfatiza dramaticamente dois pontos: de um lado, a profunda lacuna entre a capacidade humana em promover alterações atmosféricas e em gerenciar essas mudanças (NUNES, 2002) e de outro, a necessidade de alterar a maneira como a ciência e a tecnologia estão configuradas (BOLIN, 2001), visto que o atual arranjo é incapaz de responder alguns aspectos do ambiente ainda desconhecidos e ainda têm criado novos problemas. 
Por trás da visibilidade e notoriedade hodiernas das ciências atmosféricas estão os distúrbios atuais, como ondas de calor e de frio ou tempestades severas, que afetam fortemente todas as nações. Consequências ainda mais dramáticas do que as vivenciadas presentemente são apontadas por cenários projetados por modelos globais e regionais, de modo que o que deveria direcionar o progresso das ciências atmosféricas no atual momento são formas de aplicar as informações já existentes e de aprimorar novos conhecimentos, o que depende de um reconhecimento político que não seja apenas no plano teórico, e sim aplicado.

\section{REFERÊNCIAS}

ACOT, Pascal Histoire du climat: du big bang aux catastrophes climatiques. Paris: Pierrin, 2003.203p.

AGUADO, Edward; BURT, James E. Understanding weather and climate. Upper Saddle River: Prentice Hall, 1999. 474p. ALCOFORADO, Maria João. Novo Manual de Climatologia Aplicada. Revista Portuguesa de Geografia. Finisterra, v. 3, n.64, p.131-133, 1997 .

ANGELO, Claudio A espiral da norte - como a humanidade alterou a máquina do clima. São Paulo: Companhia Das Letras, 489p.

AYOADE, J.O. Introdução à climatologia para os trópicos. São Paulo: Difel, 1986. 332p.

BARBIN, Nicia Beatriz Cruz Barduchi, Inter-relação entre as mudanças climáticas, a política e o direito. Dissertação de Mestrado, Universidade Estadual de Campinas, 2006. 128p.

BOIA, Lucien. L'homme face au climat: l'imaginaire de la pluie et du beau temps. Paris: Les Belles Lettres, 2004. 207p.

BOLIN, Bert. Sustainable science and climate change. In: THE GLOBAL CHANGE OPEN SCIENCE CONFERENCE THE CHALLENGES OF A CHANGING EARTH 2001, Amsterdam, Abstracts...Amsterdam, 2001. p.6

BURROUGHS, Willian J.; CROWDER, Bob; ROBERTSON, Ted, VALLIER-TALBOT, Eleanor; WHITAKER, Richard. A guide to weather. San Francisco: Fog City Press, 1996. 288p.

BURROUGHS, William James. Does the weather really matter? the social implications of climate change. Cambridge: Cambridge University Press, 1997. 230p.

BUENO, Eduardo. A viagem do descobrimento - a verdadeira história da expedição de Cabral. Rio de Janeiro: Objetiva, 1998. $137 \mathrm{p}$.

CAMARGO, Angelo Paes de; CAMARGO, Marcelo Bento Paes de. Uma revisão analítica da evaportranspiração portencial. Bragantia, v.59, n.2, p.125-137, 2000.

CANDIDO, Daniel Henrique; NUNES, Lucí Hidalgo. Mitologia e Climatologia: um estudo das divindades relacionadas à ocorrência de tempo severo. Revista Brasileira de Climatologia. v.11, p.42-55. dez 2012. 
CROWDER, Bob. Weather-watching through the ages. In: BURROUGHS, Willian J.; CROWDER, Bob; ROBERTSON, Ted, VALLIER-TALBOT, Eleanor; WHITAKER, Richard. A guide to weather. San Francisco: Fog City Press, 1996. p.60-77.

CRUTZEN, Paul Josef. Geology of mankind. Nature, v. 15, 2002. p.3-23.

CRUTZEN, Paul Josef The "Anthropocene”. In: EHLERS, Eckart; KRAFFT, Thomas (Ed.) Earth System Science in the Anthropocene. Emerging issues and problems. Berlin: Springer Berlin Heidelberg, 2006. p.13-18.

FAGAN, Brian. Floods, famines and emperors - El Niño and the fate of civilizations. London: Pimlico, 2000.284 p.

ENCYCLOPAEDIA BRITANNICA. Pomponius Mela. Disponível em https://www.britannica.com/biography/PomponiusMela: Consultado em 13 Agosto 2018.

GEMENNE, François. Géopolittique du changement climatique. Paris: Armand Colin, 248p.

HEGERL, Gabriele C; HASSELMANN; Klaus; LATIF, Mojib. Natural climate variability and anthropogenic climate change. In: LOZÁN, JOSÉ L.; GRASSL, Hartmut; HUPFER, Peter. Climate of the 21 ${ }^{\text {st }}$. Century: changes and risks. Hamburg: Wissenschaftliche Auswertungen, 2001.p. 157-163

HELM, Carsten; SCHELLNHUBER, Hans-Joachim. The politics of the science of climate. In: LOZÁN, JOSÉ L.; GRASSL, Hartmut; HUPFER, Peter. Climate of the $\mathbf{2 1}^{\text {st }}$. Century: changes and risks. Hamburg: Wissenschaftliche Auswertungen, 2001. p. 359-362.

HOUGHTON, John Theodore. Global warming: the complete briefing. 2. Ed., reprinted Cambridge: Cambridge University Press, 2003. 251p.

JANKOVIĆ, Vladimir. Reading the skies - a cultural history of English weather, 1650-1820. Manchester: Manchester University Press, 2000. 272p.

JOHNSON, Douglas L.; LEWIS, Laurence A. Land use and degradation in historical perspective. Oxford: Blackwell Publishers, 1995. 303p.

LAMB, Hubert Horace. Climate-present, past and future. London: Methuen, 1972. 387p.

MACKENZIE, Fred Our changing planet - an introduction to earth system science and global environmental change. Englewood Cliffs: Prentice Hall, 1998. 486p.

MANNION, Antoinette Global environmental change - a natural and cultural environmental history. Routledge, 2014. $386 \mathrm{p}$.

MC KNIGHT, Tom L. Physical geography - a landscape appreciation. 5. ed. Upper Saddle River: Prentice Hall, 1996. $612 p$.

NUNES, Lucí Hidalgo. A influência do clima na história. Revista Geopantanal, Corumbá, p.15-23. 1999.

NUNES, Lucí Hidalgo. Mudanças climáticas globais. In: BORTOLOZZI, Arlêude (Org.) Debate Ambiental: do conhecimento multidimensional à perspectiva de sustentabilidade, Campinas: Nepam, 2002 pp.9-16.

NUNES, Lucí Hidalgo Interações entre a atmosfera e a sociedade: em busca de novas perspectivas. Geografia v.30, n. 1, 2005. p.199-209.

OLIVER, John E.; HIDORE, John J. Climatology - an atmospheric science. Upper Saddle River: Prentice Hall, 2002. 410 . 
PHILANDER, Samuel George El Niño, La Niña, and the Southern Oscillation. San Diego: Academic Press, 1990. 293p.

PHILANDER, Samuel George. Is the temperature rising? The uncertain science of global warming. New Jersey:

Princenton University Press, 1998. 262p.

PRIBYL, Kathleen. Farming, Famine and Plague: the impact of climate in late medieval England. Springer,, 2017. 307p.

SIMMONS, Ian G. Changing the face of the earth: culture, environment and history. Oxford: Blackwell, 1996.487 p.

SCHWÄGER, Christian The Anthropocene: The Human Era and How It Shapes Our Planet. Santa Fé/London: Synergetic Press, 2014. 248 p.

SULMAN, Felix Gad. Short and long-term changes in climate. Florida: CRC Press, 1982. 163p.

THE COLUMBIA ELECTRONIC ENCYCLOPEDIA, 6. ed. Copyright 2003, Columbia University Press. Disponível em: http://www.infoplease.com/ce6/weather/A0824229.ht

ml. Acessada em 27 Abril 2004 e 14 Agosto 2018.

WHITEHEAD, Mark. Environmental transformations: a geography of the Antropocene. New York: Routledge, 2014. $175 \mathrm{p}$.

WORLD METEOROLOGICAL ORGANIZATION Disponível em: https://public.wmo.int/en . Acessado em 23 Outubro 2018.

YNOUE, Rita Yuri, REBOITA, Michelle S.; AMBRIZZI, Tércio; SILVA, Gyrlene A.M. da. Meteorologia noções básicas.

São Paulo: Ed. Oficina de Textos, 2017.179p. 